\title{
PRODUÇÃO CIENTÍFICA SOBRE MODA NA COMUNICAÇÃO: PARA UMA BIBLIOMETRIA DE DISSERTAÇỖES E TESES
}

\author{
Priscila R. Carvalho ${ }^{1}$, Francisco Carlos Paletta ${ }^{2}$, Pedro Luiz Cortês ${ }^{3}$ \\ ${ }^{1}$ https://orcid.org/0000-0002-6929-3716, Universidade de São Paulo, Brasil. \\ preerezende@gmail.com \\ ${ }^{2}$ https://orcid.org/0000-0002-4112-5198, Universidade de São Paulo, Brasil. fcpaletta@ usp.br \\ 3 https://orcid.org/0000-0003-4160-4073, Universidade de São Paulo, Brasil. plcortes@ usp.br
}

\begin{abstract}
Resumo: A recente institucionalização do campo científico da moda e o crescente interesse no assunto observado em outros campos são o ponto inicial do projeto de pesquisa que propõe uma bibliometria de teses e dissertações produzidas nos programas de Pós-Graduação em Comunicação no Brasil. No presente trabalho, apresenta-se um levantamento preliminar do corpus de análise, com o objetivo de dimensioná-lo e de apontar questões iniciais que orientarão as próximas etapas da pesquisa empírica. Com busca realizada no catálogo de teses e dissertações da CAPES, 238 documentos foram encontrados e organizados em planilha de Excel. Três categorias puderam ser analisadas: a distribuição por Instituição de Ensino Superior, a distribuição por nível de titulação e programa, e a evolução da produção científica ao longo do tempo. A discussão resultante demonstra que a produção científica sobre moda é marcadamente concentrada em determinados programas e regiões, com avanço quantitativo acentuado entre 2015 e 2017, ampliando a interface da bibliometria entre comunicação e moda.
\end{abstract}

Palavras-chave: Organização da Informação. Bibliometria. Dissertações e Teses. Comunicação. Moda. Ciência Aberta.

\section{Introdução}

O campo científico da moda e sua institucionalização no Brasil foram impulsionados pelo surgimento e popularização dos cursos superiores que visavam atender à demanda por profissionais da cadeia de têxteis e de confecções, e pela nova configuração industrial do setor e de suas mídias a partir dos anos 90. Portanto, é um objeto recente em pesquisas acadêmicas, sendo que apenas um programa de pós-graduação no Brasil tem o tema entre suas linhas de pesquisa principais, o programa de Mestrado Acadêmico em Têxtil e Moda da Escola de Artes, Ciências e Humanidades da Universidade de São Paulo, ${ }^{1}$ criado em 2011.

Apesar disso, é possível observar o crescente interesse de pesquisadores de áreas distintas em investigar assuntos relacionados à moda e uma incipiente, porém, dispersa, produção de conhecimento científico sobre o assunto. Isso é discutido na análise bibliométrica de Silva, Café e Neto (2017), que reuniu trabalhos sobre moda advindos de programas e de pesquisadores

\footnotetext{
${ }^{1}$ Entre 2004 e 2010, o Centro Universitário Senac ofereceu o mestrado em Moda, Cultura e Arte, onde foram defendidas 39 dissertações, de acordo com Maria Claudia Bonadio (2010).
} 
pulverizados em diversas áreas do conhecimento, entre 1988 e 2013, e incluiu outros documentos afins (currículos de professores e sites dos cursos em que trabalham, apresentações em eventos científicos e publicações em periódicos da área).

A comunicação é uma das áreas que se destacam nesse universo, como mostrou o mapeamento de teses e dissertações feito por Bonadio (2010), em que a maior parte de teses de doutoramento é proveniente dessa área. Considerando isso, esse trabalho apresenta um levantamento de teses e dissertações dentro da área de comunicação para apontar a trajetória do tema e suas possíveis tendências, visando um estudo bibliométrico que organize a produção de conhecimento nessa interface.

\section{A interface da moda com a comunicação no campo científico}

Atualmente, o campo acadêmico da comunicação no Brasil conta com 50 programas de pósgraduação, de acordo com a Associação Nacional dos Programas de Pós-Graduação em Comunicação (Compós). Para Braga (2004), a comunicação, assim como todas as ciências humanas e sociais, se beneficia de articulações entre disciplinas em suas elaborações conceituais e metodológicas, e o autor trata essas articulações pela abordagem das interfaces, em que as fronteiras disciplinares não são diluídas, mas sim, "cada componente da atividade comparece com seu acervo (historicamente constituído) de práticas e de conhecimentos" (p.226).

Assim, interface é o espaço de atuação social em que os objetos e os fenômenos sociais são observados, com seus perfis de práticas e de origens diferenciados. Esses objetos têm seus processos interacionais desenvolvidos em função de suas próprias necessidades, no entanto, manifestam problemas de interação que se resolvem, privilegiadamente, pela perspectiva da área comunicacional. Em outras palavras, são problemas advindos de áreas extra comunicacionais, mas que têm a comunicação como questão (Ibid., p.226).

Para McCraken (2003), a moda, assim como a publicidade, age na movimentação de significados da cultura para os indivíduos por meio de bens e pelas práticas de consumo cotidianas. A investigação sobre a interface entre moda e comunicação vai além da subordinação de uma disciplina embrionária às disciplinas mais consolidadas, endossando um processo dialógico em que os campos contribuem uns com os outros.

\subsection{Bibliometria e as tendências de pesquisa}

Bibliometria é um conjunto de leis e princípios aplicados a métodos estatísticos e matemáticos que visam o mapeamento da produtividade científica, a partir de descrições de informação e de documentos, e quanto maior a precisão das descrições, mais relevante é a recuperação das informações (Café \& Bräscher, 2008). Com a disponibilização de sistemas de catalogação e de indexação online, que facilitam a recuperação de informações científicas, sua aplicação em outras áreas além da biblioteconomia e das ciências da informação é facilitada fornecendo conceitos científicos e elementos técnicos para medir a produção, avaliar e tomar decisões em seus respectivos campos (Côrtes \& Rodrigues, 2016, p.2).

A opção pela bibliometria fundamenta-se pela sua qualidade de englobar vários indicadores empíricos encontrados nos registros de teses e dissertações enquanto formas de comunicação acadêmica, no próprio campo e entre campos, sendo apropriada para a avaliação do crescimento e do amadurecimento de campos recentes (Borgman, 1989). A partir da análise da comunicação acadêmica 
é possível vislumbrar tendências de estudos ou o estado da arte de campos específicos e a popularidade de determinados temas (Yale \& Gilly, 1988).

\section{Metodologia}

Dadas as reflexões teóricas expostas anteriormente, o levantamento de dissertações e teses sobre moda no campo da comunicação no Brasil foi feito na base de dados da Coordenação de Aperfeiçoamento de Pessoal de Nível Superior (CAPES).

\section{Discussão dos resultados}

Três categorias de análise puderam ser estabelecidas: Instituições de Ensino Superior (IES); Nível e Programa; e Evolução da Produção. Nessas categorias já se percebem agrupamentos que indicam a moda como objeto de pesquisa da comunicação. O grupo de autores conta com 225 nomes, sendo que alguns desenvolveram o mestrado e o doutorado sobre o tema, ocorrendo duplicidades na tabela.

A categoria IES apresentou um total de 38 instituições diferentes, sendo que as 15 instituições que se destacaram estão representadas no gráfico a seguir:

Figura 1: Gráfico das 15 IES com maior número de pesquisas

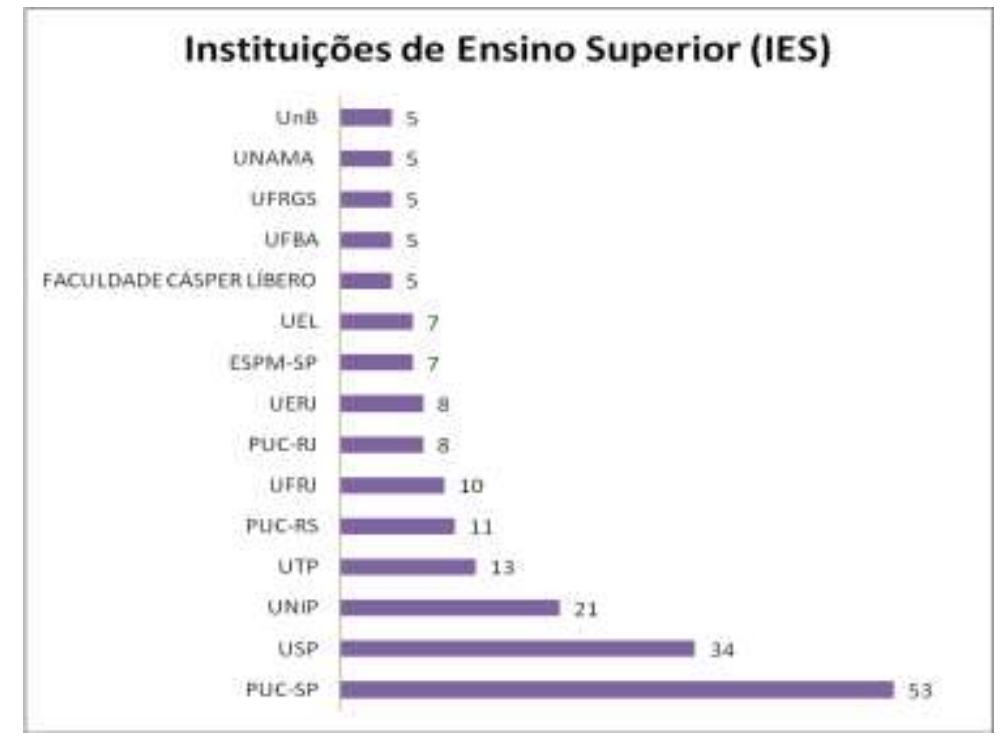

Apesar da presença de instituições de diferentes regiões do país, percebe-se que as regiões Sul e Sudeste concentram a maior parte da produção, sendo que as três primeiras estão localizadas em São Paulo e juntas são responsáveis por quase metade de todos os documentos levantados, $45 \%$. A região Sul é a segunda com maior produção, seguida pela Universidade Tuiuti do Paraná (UTP). A presença da Universidade de Brasília (UnB), da Universidade Federal da Bahia (UFBA) e da Univerdade da Amazônia (UNAMA) entre as 15 instituições de relevo demonstra que, apesar da concentração da produção, existe interesse sobre o tema nas diferentes regiões. 
A PUC-SP e seu programa de Pós-Graduação em Comunicação e Semiótica se destaca como uma instituição de referência sobre o tema, dado o volume relevante de pesquisas defendidas. Esse dado suscita a questão sobre o quanto essa instituição e sua abertura para pesquisas acerca da moda pode ter formado pesquisadores que levaram o tema para outras instituições, se firmando como fomentadora do debate na interface comunicação e moda com certa tradição, o que poderá ser verificado em uma próxima etapa da pesquisa.

O restante das insituições teve menos de 5 pesquisas defendidas sobre o tema (UFMG, UFPE e UNIMAR, com 4 cada; PUC-MG e UNESP, com 3 cada; UFF, UFPI, UFSM, UMESP, Unisinos e UNISO, com 2 cada; e USCS, PUC-B, UAM, UCB, UFC, UFG, UFPa, UFPB, UFRN, Unicamp e Universidade São Marcos, com 1 cada). Ao todo, são 41 trabalhos pontuais.

Sobre os níveis e os programas, a quantificação foi feita de acordo com a classificação apresentada nos registros da plataforma da CAPES. Sendo assim, algumas discrepâncias podem ser comentadas. De todo o conjunto de documentos, 192 deles foram defendidos no nível de Mestrado, e 46 deles em Doutorado. Ao todo, 27 entradas diferentes sobre o nível da titulação e o nome do programa foram elencadas, e as 10 mais recorrentes estão no gráfico a seguir:

Figura 1: Nível e Programa

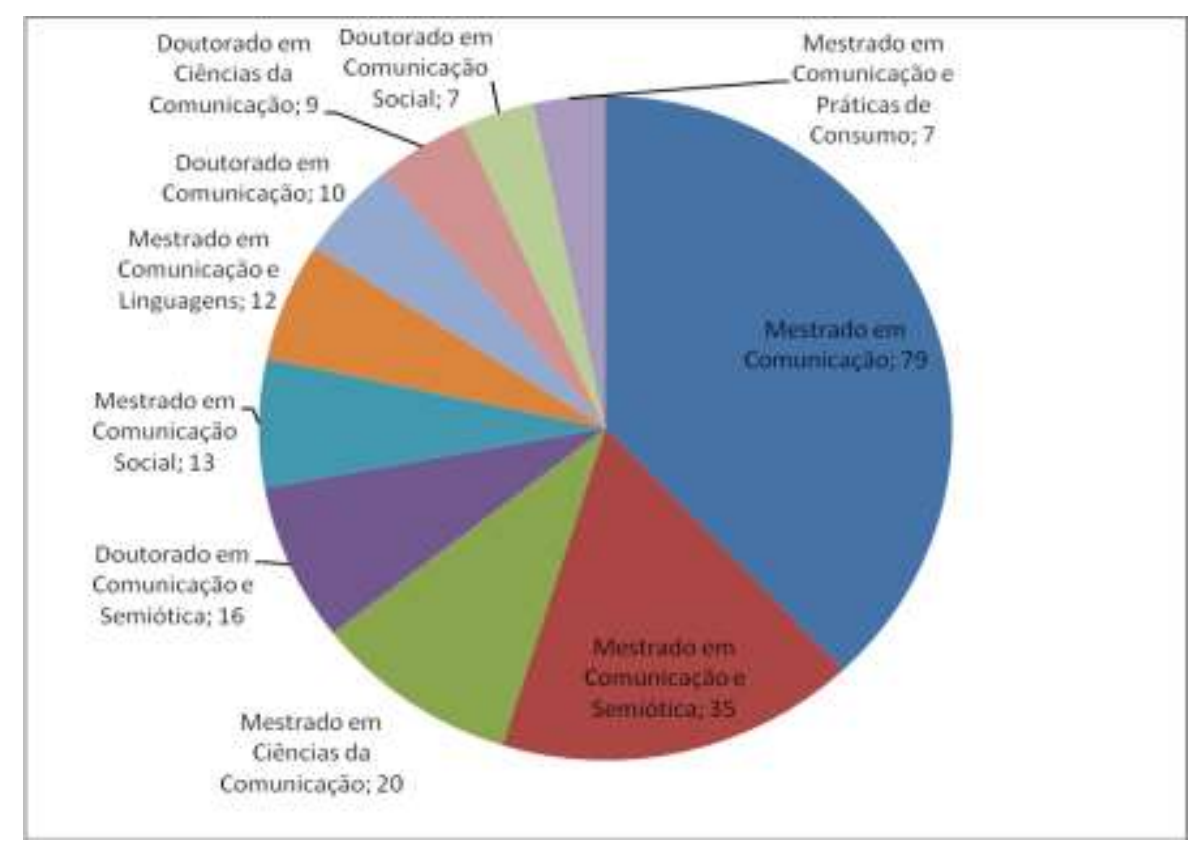

O programa com maior formação de doutores é, mais uma vez, da PUC-SP, o Doutorado em Comunicação e Semiótica. Os nomes dos programas dentro do guarda-chuva da comunicação em que moda foi tratada variam ainda entre: "Mestrado em Comunicação, Linguagens e Cultura" (5 trabalhos); "Doutorado em Comunicação e Informação" (3 trabalhos); "Mestrado em Comunicação Social: Interações Midiáticas" (3 trabalhos); "Mestrado em Comunicação e Cultura" (2 trabalhos); "Mestrado em Comunicação e Cultura Midiática" (2 trabalhos); "Mestrado em Estudos da Mídia" (2 trabalhos); "Mestrado em Mídia e Cotidiano" (2 trabalhos); "Mestrado em Relações Públicas, Propaganda e Turismo" (2 trabalhos); "Doutorado em Comunicação e Cultura Contemporânea", "Mestrado em Comunicação e Cultura Contemporânea", "Mestrado em Comunicação e Culturas Midiáticas", "Mestrado em Comunicação e Informação", "Mestrado em Comunicação Midiática", "Mestrado em Comunicação, Cultura e Amazônia", "Mestrado em Educação, Administração e Comunicação", "Mestrado em Jornalismo" e "Mestrado em Multimeios" (com 1 trabalho cada). 
Essa grande variação nos nomes dos programas pode exigir a observação mais aprofundada de suas descrições e linhas de pesquisa, além da atualização deles - indicar programas que não são oferecidos mais ou que possam ter alterado seus nomes, por exemplo.

A evolução da produção pode ser vista no gráfico a seguir:

Figura 2: Evolução da produção

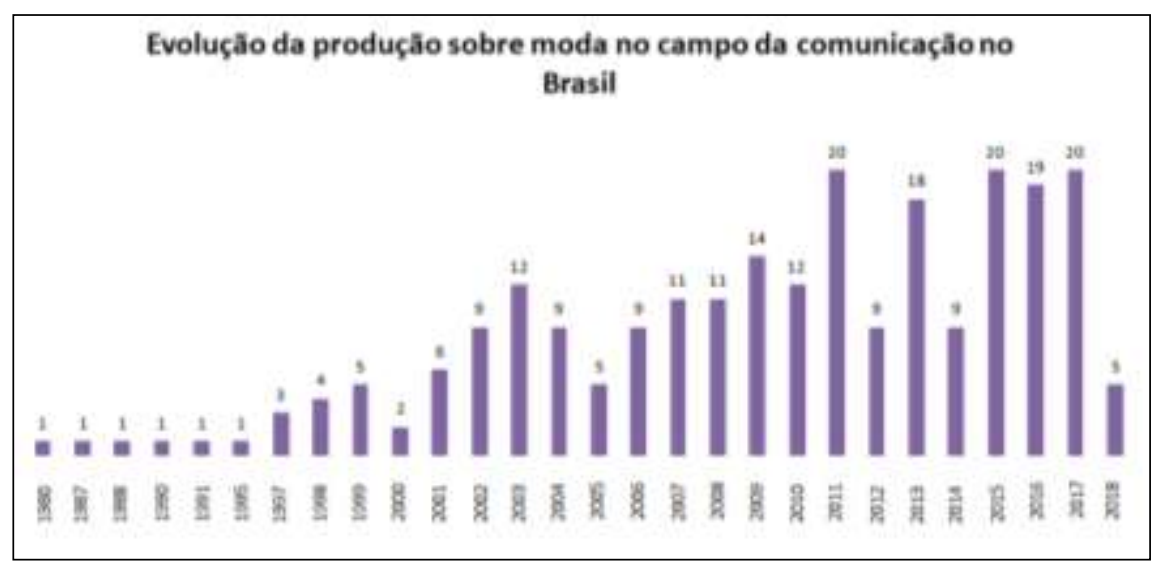

A produção de teses e dissertações sobre moda no campo da comunicação tem um crescimento contínuo. Apenas a partir de 2006 os números variam entre o mínimo de 9 e o máximo de 20 trabalhos por ano. Em 2018, o número se refere até o mês de agosto, quando o presente trabalho foi elaborado. Entre 2015 e 2017 há um pico de produção: 59 pesquisas defendidas, ou 24\% do total, ou aproximadamente o que foi produzido em 24 anos após o primeiro documento.

Muitos fatores podem ser apontados como responsáveis por esse cenário: a formação de pesquisadores que defenderam teses e dissertações sobre o tema e hoje orientam outros alunos, o conhecimento acumulado no campo sobre o objeto, o que estimularia novas pesquisas, ou mesmo o maior interesse das instituições em ter pesquisas sobre o tema, tendo em vista aspectos econômicos do comércio e da indústria. A distribuição dos nomes dos autores e dos orientadores desses trabalhos pode esclarecer o movimento ascendente da produção.

\section{Considerações finais}

As discussões sobre interface entre comunicação e moda e sobre bibliometria visaram fundamentar o levantamento de teses e dissertações que comporão o corpus de análise de um estudo bibliométrico que buscará delinear tendências de pesquisa. Algumas considerações sobre as principais instituições produtoras, os programas e o período de crescimento da produção puderam ser feitos a partir desses dados iniciais. Porém, outras relações foram vislumbradas e deverão ser elaboradas na continuidade do trabalho de investigação e de tratamento de dados.

A elaboração do banco de dados a partir dos documentos encontrados na plataforma CAPES deverá se expandir para incluir as categorias: Título, Autor, Objeto, Objetivo, Abordagens Teóricas e Métodos Aplicados, Citações e Referências Bibliográficas, de forma a resolver as questões suscitadas pela discussão desse trabalho e fornecer informações para a proposta de tendências de pesquisa. 


\section{Referências}

Bonadio, M. C. (2010). A produção acadêmica sobre moda na pós-graduação stricto sensu no Brasil. Iara Revista de Moda, Cultura e Arte - V.3 N³, 50 - 146. Disponível em:

http://www1.sp.senac.br/hotsites/blogs/revistaiara/wp-

content/uploads/2015/01/03 IARA vol3 n3 Dossie.pdf

Borgman, C. L. (1989). Bibliometrics and scholarly communication: Editor's introduction. Communication Research, 16(5), 583-599. Doi:10.1177/009365089016005002

Braga, J. L. (2004). Os estudos de interface como espaço de construção do Campo da Comunicação. Revista Contracampo, n. 10/11, 219-236. Doi: 10.22409/contracampo. v0i10/11.542

Café, L. M., Bräscher, M. (2008). Organização da informação e bibliometria. Encontros Bibli: revista eletrônica de biblioteconomia e ciência da informação, 13 (01), 54-75. Doi: 10.5007/15182924.2008v13nesp1p54

Côrtes, P. L., Rodrigues, R. (2016). A bibliometric study on “education for sustainability”. Brazilian Journal of Science and Technology, 3 (1), 1-17. Doi: 10.1186/s40552-016-0016-5

McCRACKEN, G. (2007). Cultura e consumo: uma explicação teórica da estrutura e do movimento do significado cultural dos bens de consumo. Revista de Administração de Empresas, 47(1), 99-115. Doi: $10.1590 / \mathrm{S} 0034-75902007000100014$

Silva, E.L. da; Café, L.M.A.; Neto, O.T. (2017). A institucionalização científica do campo da moda no Brasil. ECCOM, 8 (15), 133 - 152. Disponível em: http://publicacoes.fatea.br/index.php/eccom/article/view/1713

Yale, L., Gilly, M. (1988), Trends in Advertising Research: A Look at the Content of marketing-Oriented Journals from 1976 to 1985. Journal of Advertising, 17 (1), 12-22. Disponível em: http://www.jstor.org/stable/4188660.

\section{AGRADECIMENTOS}
- CAPES

- FAPESP 